\title{
REVIEW
}

\section{The placenta controls the physiology of pregnancy by increasing the half-life in blood and receptor activity of its secreted peptide hormones}

\author{
Philip Lowry and Russell Woods \\ School of Biological Sciences, University of Reading, Reading, UK \\ Correspondence should be addressed to P Lowry: p.j.lowry@reading.ac.uk
}

\begin{abstract}
An efficient functioning placenta is essential for a healthy pregnancy and yet the way this is achieved has been the subject of much discussion and confusion, particularly with the occurrence of pathological conditions such as preeclampsia, morning sickness and hyperemesis/ptyalism gravidarum. We will attempt to explain the underlying physiology and the potential roles played by the placental tachykinins, neurokinin B and endokinin.
\end{abstract}

\author{
Key Words \\ - tachykinins \\ - C-reactive protein \\ - morning sickness \\ - preeclampsia \\ - placenta
}

Journal of Molecular Endocrinology (2018) 60, R23-R30

\section{Introduction}

The placenta is a consummate endocrine organ as it secretes many biologically active peptide hormones at various times throughout the whole pregnancy. Unlike regulated secretion from other endocrine tissues, secretion from the placenta is constitutive: the synthesis and release of each peptide hormone being controlled at the level of transcription. It follows that many peptide hormones can be released differentially from even one placental cell type.

As simple peptide hormones generally have short half-lives $(<10 \mathrm{~min})$ in the circulation, under normal circumstances, this would be a considerable metabolic burden for the placenta to maintain significant blood concentrations of each peptide throughout the whole pregnancy. However, a number of known and many unidentified potential placental peptide hormones have been found to carry a posttranslational modification (PTM) containing phosphocholine (Lovell et al. 2007) that per se would lengthen the half-life.

C-reactive protein (CRP), an acute-phase protein that binds strongly to phosphocholine, is normally secreted by the liver as a stable pentamer in response to a microbial infection or to an autoimmune disease such as rheumatoid arthritis (Pepys \& Hirschfield 2003). CRP concentrations are also elevated in the blood during pregnancy and more so in preeclampsia (Cebesoy et al. 2009, Ertas et al. 2010) with the placenta recently being identified as the source (Parchim et al. 2015). As the half-life of CRP in the circulation is some $19 \mathrm{~h}$ (Vigushin et al. 1993), this would lead to a substantial increase in the half-life of 
any CRP-bound phosphocholinated placental peptide accompanied by an increase in bioactivity due to their ability to cluster their respective receptors potentially into pentamers. This topical review will attempt to elucidate in detail how these mechanisms are exploited by the placenta, particularly in relation to phosphocholinated tachykinins, to ensure a healthy pregnancy but also can cause pathological situations such as preeclampsia and hyperemesis/ptyalism gravidarum.

\section{Placental tachykinins}

The tachykinins are an ancient family of biologically active peptides and examples can be found throughout the animal and microbial kingdoms. They are distinguished by containing the common C-terminal motif: Phe-XGly-Leu-Met-amide. In humans, there are four members of the tachykinin family: substance P (SP), endokinin (EKA/B) also known as hemokinin, neurokinin A (NKA) and neurokinin $B$ (NKB). They signal through three G-protein-coupled neurokinin receptors (NK1-3R). SP and EKA/B have the same hexapeptide sequence (Gln-PhePhe-Gly-Leu-Met-amide) at their C-terminal (Fig. 1) and have preference for the NK1R. NKA has preference for the NK2R and NKB for the NK3R but there is a degree of crosstalk. NK1Rs and NK2Rs are found in the brain and in the periphery but the NK3Rs are mainly found in the periphery.

As examples of biologically active peptides, the tachykinins are unique in being expressed throughout the nervous, immune and endocrine systems and are involved in the regulation of a diverse range of physiological and pathological processes (Steinhoff et al. 2014); NKB and EKB in particular are found in the placenta (Page et al. 2000, 2003).

\section{Placental neurokinin B}

The first tachykinin gene found to be expressed in the human placenta was the TAC3 gene that encodes the
NKB precursor. A radioimmunoassay for the processed NKB decapeptide detected material in the extracts of the human placenta and in the blood of pregnant women. Elevated concentrations of the peptide in the nanomolar range were found in blood of women suffering from preeclampsia (Page et al. 2000), an observation confirmed by others (Geissbuehler et al. 2007, Zulfikaroglu et al. 2007).

In a healthy pregnancy, normal stimulation of maternal peripheral NK3Rs would cause a modest increase in heart rate (Thompson et al. 1998), contraction of the hepatic portal vein (Mastrangelo et al. 1987) and mesenteric blood vessels (D'Orleans-Juste et al. 1991). This would conspire to improve the mother's blood circulation to other organs such as the uterus. The poorly implanted placenta seen in preeclampsia responds by hypersecreting NKB with overstimulation of NK3Rs resulting in hypertension. NKB has also been shown to cause lung and liver oedemas similar to that seen in preeclampsia (Grant et al. 2002). However, the NKB placental peptide did not react with some antibodies raised against the natural brain form of the peptide and mass spectrometric analysis revealed that it has a larger mass and indicated that it contained a PTM containing phosphocholine (Lovell et al. 2007). Further mass spectrometric analysis suggested that the PTM was a variant of desacetyl platelet activating factor attached by an ester bond to the side chain of the aspartate residue at position 4 in the NKB decapeptide (Lowry 2011). Although NKB has always been assumed to be the natural ligand for the NK3R, the simple decapeptide is only a partial agonist and most receptor studies use synthetic homologues such as senktide that is a full NK3R agonist. Thus, it was initially assumed that the phosphocholinated PTM added by the placenta to NKB converted it into a full agonist for the NK3R. Significantly, there is a candidate phosphocholine transferase B enzyme which is uniquely expressed in the placenta in the pregnant female where it is associated with the endoplasmic reticulum, the site of secretory peptide synthesis (Lykidis et al. 1998, 1999).

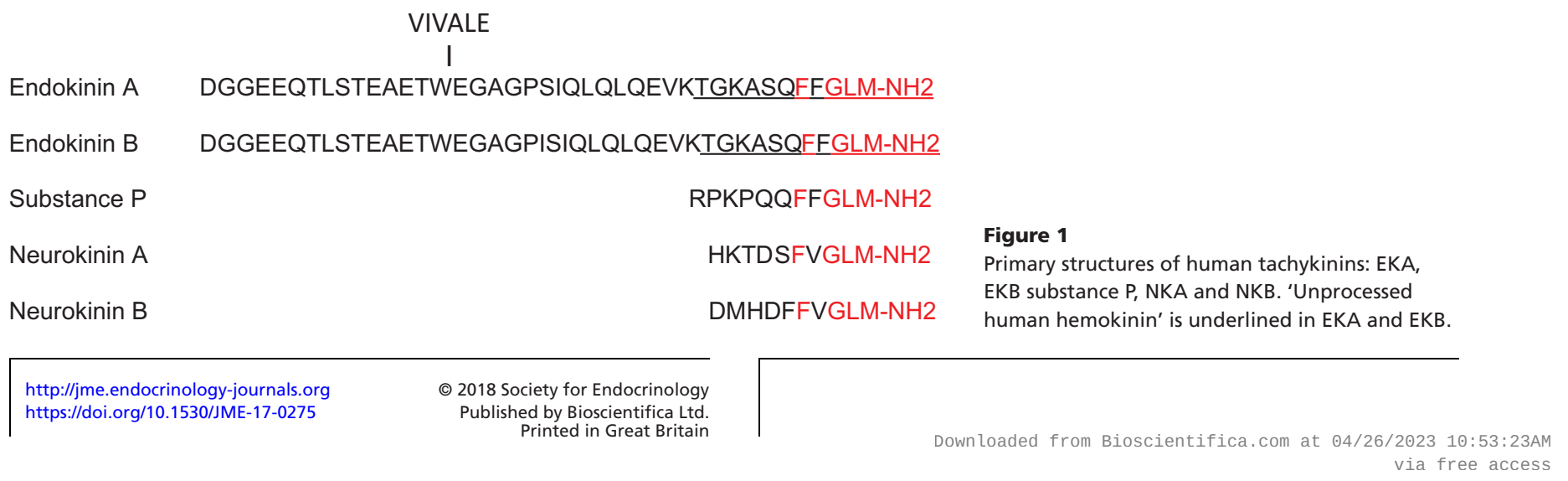


As a phosphocholinated protein, ES62, secreted by a filarial parasitic nematode had previously been shown to aid its survival in the host, with the phosphocholine moiety conferring the activity (Harnett et al. 2003), it was also thought that the placental secretion of phosphocholinated NKB may help the placenta to avoid surveillance by the mother's immune system (Lowry 2008).

NKB however is not the only placental peptide/ protein that carries a phosphocholine PTM. In the rat, placental pro-corticotropin-releasing factor (CRF), proactivin, follistatin and pro-hemokinin (endokinin) were also found to be modified, as well as a significant number of other as yet unidentified placental peptides/proteins (Lovell et al. 2007) suggesting that this PTM represents a fundamental mechanism that regulates peptide hormone longevity in blood and potentially modulates their biological activity.

\section{The significance of placental CRP}

CRP, an acute-phase protein normally synthesised in the liver, naturally binds strongly to phosphocholine, and in healthy individuals the blood concentrations are very low. CRP levels do however increase rapidly in response to inflammation, whether from microbial infection or by tissue damage (Pepys \& Hirschfield 2003). Figure 2 shows the structure of CRP with five protomers formed into a stable pentamer. It is important to note that all five binding sites for phosphocholine on each protomer face in the same direction (Thompson et al. 1999) so that any bound phosphocholinated placental peptides would follow suit. CRP circulates as this pentamer and binds to phosphocholine on the surface of microbes, the resulting aggregation initiating the immune response. Binding to exposed phosphatidylcholine on damaged tissue cell membranes assists in their removal but high levels of CRP can persist under such conditions as rheumatoid arthritis.

Elevated concentrations of CRP are also found in the blood of pregnant women and more so in preeclampsia (Cebesoy et al. 2009, Ertas et al. 2010) but notably it has recently been shown that the main source in pregnancy is the placenta where it appears to be synthesised in the same region of the syncytiotrophoblast as NKB (Parchim et al. 2015). It was found that infusion of CRP into mice to mimic the concentrations found in human preeclampsia resulted in only pregnant animals showing symptoms of preeclampsia, namely hypertension, proteinuria, kidney and placental damage and increased levels of sFlt-1. More importantly, it was found that these CRP-induced symptoms in the pregnant mice were attenuated by administration of either an NK3R antagonist or inhibition of the placental phosphocholine transferase B enzyme and lead to the conclusion that it is the coordinate action of CRP and PC-NKB that causes the symptoms of preeclampsia (Parchim et al. 2015). The simple binding of circulating PC-NKB to CRP, a protein with a half-life of $19 \mathrm{~h}$ (Vigushin et al. 1993), would result in a very significant increase in the half-life of this small placental tachykinin peptide from just a few minutes to several hours permitting the placenta to maintain significant blood concentrations at relatively low secretion rates.

Receptor clustering is a common trigger for a number of signalling events. It is known that aggregation or clustering of peptide hormone receptors can increase potency and/or change downstream signalling and significantly alter the physiological response (Caré \& Soula 2011, Dustin \& Groves 2012, Goyette \& Gaus 2016). This could be the case with CRP/PC-NKB at the NK3Rs. PC-NKB bound to CRP could also prevent receptor endocytosis leading to an increase in potency.

To summarise in a normal healthy pregnancy, low concentrations of CRP-bound PC-NKB at peripheral NK3Rs result in mild NK3R clustering into pentamers in the heart, hepatic portal vein and mesenteric vessels leading to the changes in the mother's vasculature to the benefit of the uterus and placenta. Oversecretion of PC-NKB and CRP by a distressed placenta to improve survival of the feto/placental unit would lead to overstimulation and clustering of NK3Rs which would then give rise to the symptoms of preeclampsia. The observation that inhibiting the synthesis of placental phosphocholine transferase and/or blocking the NK3R reduced the severity of symptoms of preeclampsia in CRP-treated pregnant mice (Parchim et al. 2015) lends considerable weight to this hypothesis.

\section{Placental endokinin}

Although the gene for substance $\mathrm{P}$ is not expressed in the human placenta, the TAC4 gene for the stronger NK1R agonist, endokinin, is expressed. There are four splice variants: $\alpha$-TAC4, $\beta$-TAC4, $\gamma$-TAC4 and $\delta$-TAC4 which are expressed in many tissues throughout the body. The $\gamma$-TAC4 and $\delta$-TAC4 variants are highly expressed in the placenta (Page et al. 2003). The translated pro-endokinin peptide precursor is unusual as it does not contain the classical double basic consensus sequence upstream of the main tachykinin peptide region. Thus, rather than being processed to an eleven- or ten-residue-long peptide 


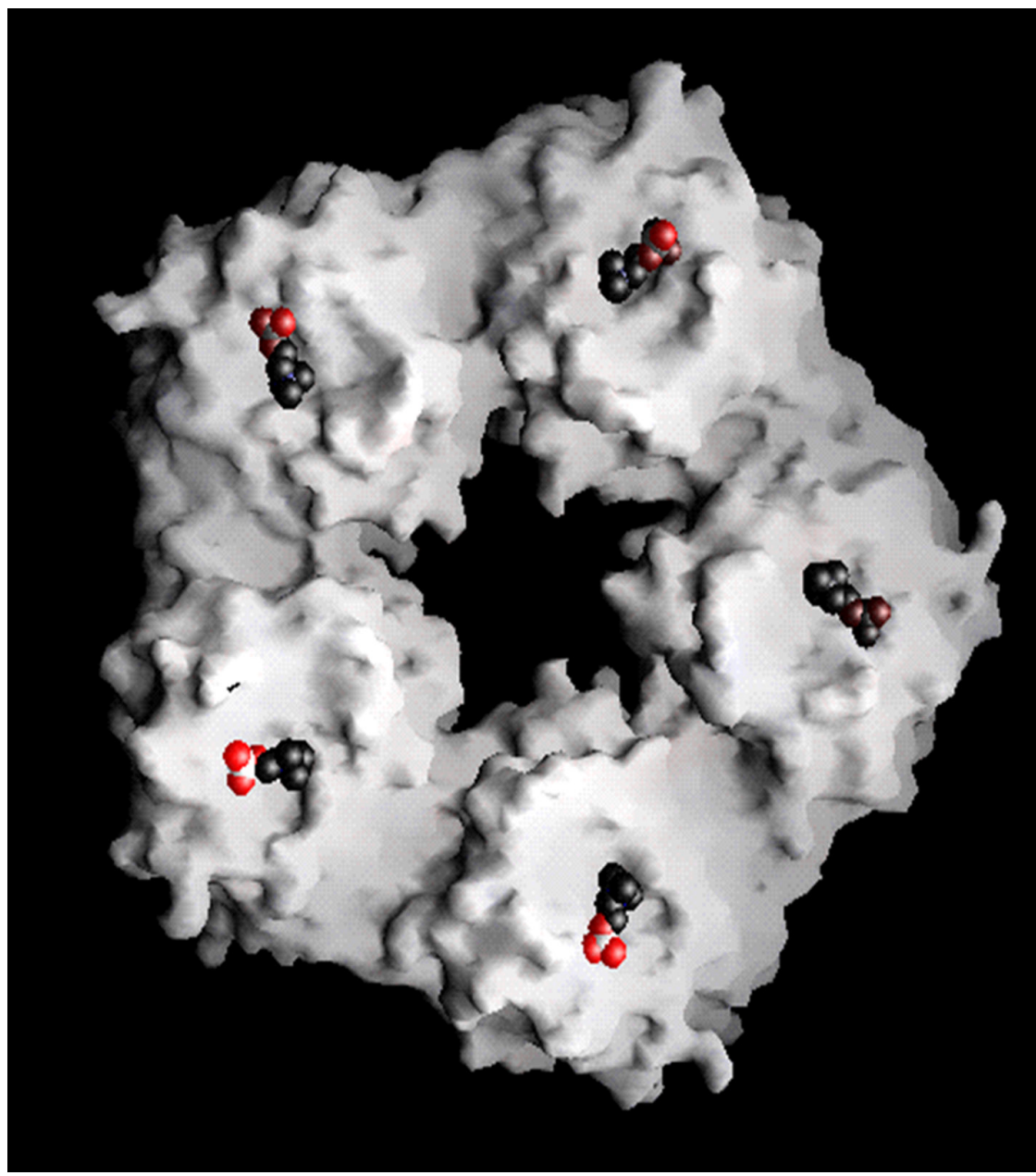

Figure 2

Space-filled 3D model (courtesy of Mark Pepys) of the choline-reactive protein pentamer showing phospho-choline bound to each protomer (Thompson et al. 1999). as with substance $\mathrm{P}$ and $\mathrm{NKB}$, it has a long N-terminal extension. The $\alpha$-TAC splice variant would give rise to the 47 mer peptide, EKA (Fig. 1). The more widely expressed $\beta$-, $\gamma$ - and $\delta$-TAC spice variants would lead to the secreted mature processed peptide, EKB, some 41 residues in all. EKA contains six extra residues inserted between $\operatorname{Tr} \mathrm{P}^{15} / \mathrm{Glu}^{16}$ with the rest of the sequence, the same as EKB (Fig. 1). In both EKA and EKB, the arginine position (37 in EKA and 31 in EKB) has been substituted with threonine that automatically removes the double basic processing site which is found upstream of the tachykinin motif in the SP, NKA and NKB precursors. The so-called human hemokinin (Thr-Gly-Lys-Ala-Ser-Gln-Phe-PheGly-Leu-Met- $\mathrm{NH}_{2}$ ), the last 11 residues underlined in EKA and EKB (Fig. 1) originally proposed (Kurtz et al. 2002) would not exist in vivo as processing at single lysine residues, has never been reported. Thus, it is not surprising that despite the availability of a commercial immunoassay to the 11 mer hemokinin, there have been no reports of significant concentrations of hemokinin in human samples. However, a two-site immunometric assay (one antibody raised against residues $12-30$ and the second raised against residues $32-41$ of EKB) detected significant concentrations of EKB immunoreactivity in human placental extracts (Page et al. 2003). Like its rat equivalent, placental human EKB was also found to be phosphocholinated and being a longer peptide (41mer vs 10mer) eluted much later than placental NKB on C8 HPLC (D Butlin \& P Lowry, unpublished observations). In fact, the natural N-terminal extension would increase potency of EKB at the NK1R, as a synthetic EKB-32mer with an extended N-terminal, EKB (10-41), was considerably more potent than substance $\mathrm{P}$ at this receptor (Page et al. 2003). Both the human endokinin and the rat N-terminally extended endokinin/hemokinin have a single aspartate residue (the amino acid with the PTM attached in placental NKB (Lowry 2011)) at their respective N-terminals for the potential attachment of the phosphocholine containing PTM by the placenta. Again, like PC-NKB, PC-EKB being bound to CRP would lead to a significant increase in its half-life in the circulation and result in clustering of its preferred receptors, the NK1Rs. 


\section{Tachykinins in vascularisation and vasodilation}

Although NKB was originally proposed to be the tachykinin secreted by the placenta that would cause local beneficial vasodilation via NK1Rs (Brownbill et al. 2003, Laliberte et al. 2004), the much stronger placental NK1R agonist, EKB, is clearly a more suitable candidate. Moreover, phosphocholinated EKB in consort with placental CRP would increase its half-life from minutes to several hours and also result in NK1 receptor clustering which could be the stimulus that creates the important neovascularisation in both the placenta and the uterus that is vital for efficient diffusion of gases, nutrients and waste products throughout pregnancy. Thus, both placental phosphocholinated tachykinins, complexed with CRP, in stimulating NK1 and NK3 receptors could also be responsible for the beneficial changes seen in the mother's peripheral blood flow in a healthy pregnancy. This involves improved cardiac output, general arterial compliance, an increase in renal plasma flow and a reduction in vascular resistance and blood pressure. These alterations begin soon after conception, peak by the beginning of the second trimester and persist throughout gestation. The resulting fall in ventricular afterload initiates the large increase in cardiac output and, subsequently, the expansion of plasma volume: changes that are associated with a healthy pregnancy (Conrad \& Lindheimer 1999).

\section{NK1Rs in morning sickness and chemotherapy-induced emesis}

Vomiting or emesis has been recognised for centuries as a protective reflex after ingesting poisonous materials. The one condition in which emesis has been the cause of much distress and confusion (particularly regarding what benefit it can impart) is pregnancy. In extreme cases (hyperemesis gravidarum), it can lead to the death of both mother and foetus.

However, it has been reported that systemic administration of the NK1R agonist, substance P, into experimental animals causes emesis (Carpenter et al. 1984, Knox et al. 1993) and its topical application to the area postrema (the part of the medulla oblongata below the blood-brain barrier) in the ferret induced retching after a latency of about 30s (Andrews 1994) and in the dog induced firing in neurones in about $48 \%$ of the neurones tested (Carpenter et al. 1983).
Although the TAC1/substance P gene is not expressed in the human placenta (Page et al. 2003), the potent activity of CRP-bound PC-EKB released by the placenta clustering both local NK1Rs and those in the area postrema would provide an explanation for the putative link between a healthy placenta and emesis of pregnancy. In fact, a recent comprehensive study showed that women who experienced morning sickness had healthier pregnancies and concluded that the viability of the placenta was linked to emesis (Hinkle et al. 2016). It is intriguing to note here that there is a remarkable coincidence in the timing of emesis and changes in the mother's vasculature (Conrad \& Lindheimer 1999) covered in the previous section adding to the notion of the involvement of placental EKB stimulating systemic NK1Rs for a healthy pregnancy.

Another supportive coincidence is the observation that women who do not experience emesis during pregnancy, presumably due to natural downregulation or reduced sensitivity of their brain NK1 emesis receptors, have a much better tolerance to chemotherapy for the treatment of cancer later in life (Bouganim et al. 2012) suggesting that the same NK1 receptors are involved. Patients, who do experience chemotherapy-induced emesis, do however respond well when treated with NK1R antagonists such as aprepitant (Diemunsch et al. 2009, Dos Santos et al. 2012).

\section{Salivation}

The excessive salivation during pregnancy (ptyalism gravidarum), which invariably accompanies hyperemesis gravidarum, provides further evidence for the secretion of the NK1R agonist EKB by the placenta. The sialagogic action of substance $\mathrm{P}$ was first recognised 50 years ago, when a peptide with this activity was isolated from the hypothalamus and was found to have the same amino acid composition as substance $\mathrm{P}$ isolated from the gut (Leeman \& Hammerschlag 1967). More recent pharmacological studies have confirmed that salivation is mediated through the NK1 receptor (Giuliani et al. 1988).

\section{Drug treatment}

Given the many physiological roles of tachykinins, the use of freely diffusible small-molecule NK1R antagonists for the alleviation of the symptoms of morning sickness and salivation should be avoided as they could have adverse effects on the development of both the placenta and the foetus. However, in women previously diagnosed 
with diabetes insipidus, the use of the orally administered peptide, DDAVP (desmopressin), is safe during pregnancy. Enough DDAVP survives digestion (due to its resistant D-amino acid content) to be efficacious, but it does not cross the placenta into the foetus in appreciable amounts. Similarly, sendide, an NK1R antagonist, is also a protected peptide and reduces cisplatin-induced emesis in ferrets by targeting NK1Rs in the gut and the area postrema (Minami et al. 1998). As sendide would not be expected to cross into the foetus, could it become the drug of choice to treat morning sickness and sialorrhoea? In view of possible negative effects in the mother and feto/placental unit, it may not be advisable for 24 -h dosage in extreme cases of hyperemesis gravidarum, but it may provide enough temporary relief for pregnant women to have nourishment by mouth, avoiding intravenous feeding/ rehydration and enabling arrest of the self-sustaining vomiting reflex. A sendide-containing mouthwash could however be a safe treatment for sialorrhoea.

\section{Lung EKB, smoking in pregnancy and chemotherapy}

Unlike TAC1 (the substance P gene), the TAC4 splice variants, as well as being expressed in most body tissues, were also expressed in all but one of the 15 tumour (including the placental BeWo) cell lines studied (Page et al. 2003), suggesting that EKA and EKB would be synthesised and released from the associated tissue. Of particular interest was the expression of $\beta$-TAC4 and $\gamma$-TAC4 in normal lung tissue and in both lung tumour cell lines screened, $\gamma$ TAC4 in A549 and $\beta$-TAC4, $\gamma$-TAC4 and $\delta$-TAC4 in U937. Humans as well as animals generally try to escape from smoke (and thus avoid getting burnt in forest fires, etc.) as inhalation induces nausea. This is probably the reason why many people never take up smoking tobacco or inhale the smoke as they have sensitive NK1Rs in their area postrema that are easily stimulated making them feel nauseous. Thus, could it be the potent NK1R agonist, $\mathrm{EKB}$, released from the lungs into the circulation during smoke inhalation, stimulating the NK1 receptors in the area postrema that initiates this nausea? In a recent preliminary study, the concentration of plasma EKB immunoreactivity increased nearly 30 -fold in a nonsmoker after inhalation of tobacco and remained elevated two hours later when nausea was still being experienced (Vaiyapuri et al. 2017). Why some individuals can keep on inhaling tobacco smoke without experiencing nausea maybe due to downregulation or natural insensitivity of the same NK1 receptors while simultaneously they become addicted to nicotine. Indeed, it is well known that women who smoke during pregnancy are afforded considerable protection against morning sickness (Klebanoff et al. 1985, Little \& Hook 1979) and preeclampsia (Conde-Agudelo et al. 1999) suggesting that both NK1 and NK3 receptors have been downregulated and desensitised, respectively. Vomiting and nausea induced by chemotherapy are also lower in people who smoke tobacco, again suggesting the same NK1Rs that are involved (Bouganim et al. 2012).

The offspring of women who smoke during pregnancy suffer from pre- and postnatal growth retardation and increased risks of placental mortality, morbidity and behavioural anomalies (Abel 1980). The poor placental outcome may be due to the same EKB released from the lungs during smoking downregulating the NK1Rs or displacing PC-EKB from local placental/uterine NK1Rs, preventing the coordinated action of CRP/PC-EKB and clustering these receptors into pentamers, the proposed event necessary for the stimulation of neovascularisation and a healthy placenta. It is also possible that the high lung endokinin concentrations in uterine blood disrupt the local concentration gradient of placental endokinin that may be necessary for the correct directional growth of the spiral arteries in the small finger-like projections that ensure the efficient exchange of nutrients, gases and waste products at the placental/uterine interface.

\section{Other placental phosphocholinated neuropeptides}

Other placental peptide precursors that were found to contain the phosphocholine immunoreactivity were pro-opiomelanocortin, follistatin, pro-activin and proCRFs, but in the latter two, neither of the processed active peptides, activin and CRF, possessed the PTM (Lovell et al. 2007). In the case of placental CRF, it circulates and is bound to a specific inhibiting binding protein that is also expressed in the human placenta (Petraglia et al. 1993). In late pregnancy, concentrations of the CRF-inhibiting binding protein decrease, leading to a rapid increase in circulating levels of free bioactive CRF at the onset of parturition (Mclean et al. 1995).

In the Lovell et al.'s (2007) study, there did however seem to be many other placental peptides which were immunoreactive for phosphocholine, with the probability of their coordinate action with CRP at target receptors in the mother. Thus, it is possible that the cumulative effect of certain cocktails of phosphocholinated neuropeptides bound to CRP of placental origin could stimulate certain brain receptors sufficiently enough to be responsible 
for changes of behaviour that are experienced by many women during pregnancy. Withdrawal of this stimulus postpartum could contribute to postnatal depression.

\section{Concluding comments}

The placenta as an endocrine organ, and particularly as a source of peptide hormones, is widely acknowledged. The potential futility of expending energy on the continual production of molecular messengers that possess such short survival times in the plasma has not, however, been considered. We propose that the placenta modulates physiology through a unique PTM of the hormones that it produces. This not only extends the half-life of placentalderived hormonal signals, but changes the nature or enhances their actions. While this appears to form a fundamental mechanism that controls physiological changes required for healthy pregnancy, overreactivity in some may underlie some of the most prevalent pregnancyrelated disorders.

\section{Declaration of interest}

The authors declare that there is no conflict of interest that could be perceived as prejudicing the impartiality of this review.

\section{Funding}

This work did not receive any specific grant from any funding agency in the public, commercial or not-for-profit sector

\section{Acknowledgements}

The authors wish to thank Sir Mark Pepys FRS for the picture of the 3D model of CRP, Drs A Bicknell and W Kaiser for helpful discussion and Profs. $J$ Gibbins and $\mathrm{F}$ Cunningham for critical reading of the manuscript.

\section{References}

Abel EL 1980 Smoking during pregnancy: a review of effects on growth and development of offspring. Human Biology 52 593-625.

Andrews PLR 1994 5-HT3 receptor antagonists and antiemesis. In 5-HT3 Receptor Antagonists, pp 255-317. Eds FD King, B Jones \& GJ Sanger. Boca Raton, FL, USA: CRC Press.

Bouganim N, Dranitsaris G, Hopkins S, Vandermeer L, Godbout L, Dent S, Wheatley-Price P, Milano C \& Clemons M 2012 Prospective validation of risk prediction indexes for acute and delayed chemotherapy-induced nausea and vomiting Current. Oncology 19 414-421.

Brownbill P, Bell NJ, Woods RJ, Lowry PJ, Page NM \& Sibley CP 2003 Neurokinin B is a paracrine vasodilator in the human fetal placental circulation. Journal of Clinical Endocrinology and Metabolism $\mathbf{8 8}$ 2164-2170 (https://doi.org/10.1210/jc.2002-021727)

Caré BR \& Soula HA 2011 Impact of receptor clustering on ligand binding. BMC Systems Biology 548.
Carpenter DO, Briggs DB \& Strominger N 1983 Cell responses of neurons of canine area postrema to neurotransmitters and peptides. Molecular Neurobiology 3 113-126. (https://doi.org/10.1007/ BF00735276)

Carpenter DO, Briggs DB \& Strominger N 1984 Peptide induced emesis in dogs. Behavioural Brain Research 11 277-281. (https://doi. org/10.1016/0166-4328(84)90220-1)

Cebesoy FB, Balat O, Dikensoy E, Kalayci H \& Ibar Y 2009 CA-125 and CRP are elevated in preeclampsia. Hypertension in Pregnancy $\mathbf{2 8}$ 201-211. (https://doi.org/10.1080/10641950802601187)

Conde-Agudelo A, Althabe F, Belizán JM \& Kafury-Goeta AC 1999 Cigarette smoking during pregnancy and risk of preeclampsia: a systematic review. American Journal of Obstetrics and Gynecology 181 1026-1035. (https://doi.org/10.1016/S0002-9378(99)70341-8)

Conrad KP \& Lindheimer MD 1999 Renal and cardiovascular alterations. In Chesley's Hypertensive Disorders in Pregnancy, 2nd edn, pp 263-326. Eds MD Lindheimer, JM Roberts \& FG Cunningham. Stamford, CT, USA: Appleton \& Lange.

Diemunsch P, Joshi GP \& Brichant JF 2009 Neurokinin receptor antagonists in the prevention of postoperative nausea and vomiting. British Journal of Anaesthesia 103 7-13. (https://doi.org/10.1093/bja/ aep125)

D'Orleans-Juste P, Claing A, Telemaque S, Warner TD \& Regoli D 1991 Neurokinins produce selective venoconstriction via NK-3 receptors in the rat mesenteric vascular bed. European Journal of Pharmacology 204 329-334.

Dos Santos LV, Souza FH, Brunetto AT, Sasse AD \& da Silveira Nogueira Lima JP 2012 Neurokinin-1 receptor antagonists for chemotherapyinduced nausea and vomiting: a systematic review. Journal of the National Cancer Institute 104 1280-1292. (https://doi.org/10.1093/ jnci/djs335)

Dustin ML \& Groves JT 2012 Receptor signalling clusters in the immune synapse. Annual Review of Biophysics 41 543-556. (https://doi. org/10.1146/annurev-biophys-042910-155238)

Ertas IE, Kahyaoglu S, Yilmaz B, Ozel M, Sut N, Guven MA \& Danisman N 2010 Association of maternal serum high sensitive C-reactive protein level with body mass index and severity of pre-eclampsia at third trimester. Journal of Obstetrics and Gynaecology Research 36 970-977. (https://doi.org/10.1111/j.1447-0756.2010.01279.x)

Geissbuehler V, Moser R, Zimmermann K, Hillermann R, Czarniecki J, Gebhardt SG \& Eberhard J 2007 Altered plasma neurokinin B levels in patients with pre-eclampsia. Archives of Gynecology and Obstetrics 276 151-157. (https://doi.org/10.1007/s00404-0060316-y)

Giuliani S, Maggi CA, Regoli D, Drapeau G, Rovero P \& Meli A 1988 NK-1 receptors mediate the tachykinin stimulation of salivary secretion: selective agonists provide further evidence. European Journal of Pharmacology 15 377-379. (https://doi.org/10.1016/00142999(88)90022-2)

Goyette J \& Gaus K 2016 Mechanisms of protein nanoscale clustering. Current Opinion in Cell Biology 44 1-7.

Grant AD, Akhtar R, Gerard NP \& Brain SD 2002 Neurokinin B induces oedema formation in mouse lung via tachykinin receptorindependent mechanisms. Journal of Physiology 543 1007-1014. (https://doi.org/10.1113/jphysiol.2002.018846)

Harnett W, Harnett MM \& Byron O 2003 Structural/functional aspects of ES-62- a secreted immunomodulatory phosphorylcholine containing filarial nematode glycoprotein. Current Protein and Peptide Science 4 59-72. (https://doi.org/10.2174/ 1389203033380368)

Hinkle SN, Mumford SL, Grantz KL, Silver RM, Mitchell EM, Sjaarda LA, Radin RG, Perkins NJ, Galai N \& Schisterman EF 2016 Association of nausea and vomiting during pregnancy with pregnancy loss: a secondary analysis of a randomized clinical trial. JAMA Internal Medicine 176 1621-1627. (https://doi.org/10.1001/ jamainternmed.2016.5641) 
Klebanoff MA, Koslowe PA, Kaslowe R \& Rhoads GG 1985 Epidemiology of vomiting in early pregnancy. Obstetrics and Gynecology 66 612-616.

Knox AP, Strominger NL, Battles AH \& Carpenter DO 1993 Behavioral studies of emetic sensitivity in the ferret. Brain Research Bulletin $\mathbf{3 1}$ 477-484. (https://doi.org/10.1016/0361-9230(93)90112-O)

Kurtz MM, Wang R, Clements MK, Cascieri MA, Austin CP, Cunningham BR, Chicchi GG \& Liu Q 2002 Identification, localization and receptor characterization of novel mammalian substance P-like peptides. Gene 296 205-212. (https://doi. org/10.1016/S0378-1119(02)00861-2)

Laliberte C Dimarso L, Morrish DW \& Kaufman S 2004 Neurokinin B causes concentration-dependent relaxation of isolated human placental resistance vessels Regulatory Peptides 117 123-126. (https:// doi.org/10.1016/j.regpep.2003.10.032)

Leeman SE \& Hammerschlag R 1967 Stimulation of salivary secretion by a factor extracted from hypothalamic tissue. Endocrinology $\mathbf{8 1}$ 803-810. (https://doi.org/10.1210/endo-81-4-803)

Little RE \& Hook EB 1979 Maternal alcohol and tobacco consumption and their association with nausea and vomiting during pregnancy. Acta Obstetrica et Gynaecologica Scandinavica 58 15-17. (https://doi. org/10.3109/00016347909154905)

Lovell TM, Woods RJ, Butlin DJ, Brayley KJ, Manyonda IT, Jarvis J, Howell S \& Lowry PJ 2007 Identification of a novel mammalian post-translational modification, phosphocholine, on placental secretory polypeptides. Journal of Molecular Endocrinology 39 189-198. (https://doi.org/10.1677/JME-07-0007)

Lowry PJ 2008 The placenta is simply a neuroendocrine parasite. Journal of Neuroendocrinology 20 700-704. (https://doi. org/10.1111/j.1365-2826.2008.01737.x)

Lowry P 2011 1-O-alkenyl-sn-glyceryl-3-phosphorylcholine may be a novel posttranslational modification used by the placenta. Biopolymers 96 189-192. (https://doi.org/10.1002/bip.21407)

Lykidis A, Murti KG \& Jackowski S 1998 Cloning and characterization of a second human CTP:phosphocholine cytidylyltransferase. Journal of Biological Chemistry 273 14022-14029. (https://doi.org/10.1074/ jbc.273.22.14022

Lykidis A, Baburina I \& Jackowski S 1999 Distribution of CTP:phosphocholine cytidylyltransferase (CCT) isoforms. Journal of Biological Chemistry 274 26992-27001. (https://doi.org/10.1074/ jbc.274.38.26992)

Mastrangelo D, Mathison R, Huggel HJ, Dion S, D'Orleans-Juste P, Rhaleb NE, Drapeau G, Rovero P \& Regoli D 1987 The rat isolated portal vein: a preparation sensitive to neurokinins, particularly neurokinin B. European Journal of Pharmacology 134 321-326. (https://doi.org/10.1016/0014-2999(87)90363-3)

McLean M, Bisits A, Davies J, Woods R, Lowry PJ \& Smith R 1995 A placental clock controlling the length of human pregnancy. Nature Medicine 1 460-463. (https://doi.org/10.1038/nm0595-460)
Minami M, Endo T, Kikuchi T, Ihira T \& Hirafuji M 1998 Antiemetic effects of sendide, a peptide tachykinin NK 1 receptor antagonist, in the ferret. European Journal of Pharmacology 363 49-55. (https://doi. org/10.1016/S0014-2999(98)00784-5)

Page NM, Woods RJ, Gardiner SM, Lomthaisong K, Gladwell RT, Butlin DJ, Manyonda IT \& Lowry PJ 2000 Excessive placental secretion of neurokinin B during the third trimester causes preeclampsia. Nature 405 797-800. (https://doi.org/10.1038/35015579)

Page NM, Bell NJ, Gardiner SM, Manyonda IT, Brayley KJ, Strange PG \& Lowry PJ 2003 Characterization of the endokinins: human tachykinins with cardiovascular activity. PNAS 100 6245-6250. (https://doi.org/10.1073/pnas.0931458100)

Parchim NF, Wang W, Iriyama T, Ashimi OA, Siddiqui AH, Bakckwell S, Sibai B, Kellems RE \& Xia Y 2015 Neurokinin 3 receptor and phosphocholine transferase missing factors for pathogenesis of C-reactive protein in preeclampsia. Hypertension 65 430-439. (https://doi.org/10.1161/HYPERTENSIONAHA.114.04439)

Pepys MB \& Hirschfield GM 2003 C-reactive protein: a critical update. Journal of Clinical Investigation 111 1805-1812. (https://doi. org/10.1172/JCI200318921)

Petraglia F, Potter E, Cameron VA, Sutton S, Behan DP, Woods RJ, Sawchenko PE, Lowry PJ \& Vale W 1993 Corticotropin-releasing factor-binding protein is produced by human placenta and intrauterine tissues. Journal of Clinical Endocrinology and Metabolism 77 919-924.

Steinhoff MS, von Mentzer B, Geppetti P, Pothoulakis C \& Bunnett NW 2014 Tachykinins and their receptors: contributions to physiological control and the mechanisms of disease. Physiological Reviews 94 265-301. (https://doi.org/10.1152/physrev.00031.2013)

Thompson GW, Hoover DB, Ardell JL \& Armour JA 1998 Canine intrinsic cardiac neurons involved in cardiac regulation possess NK1, NK2 and NK3 receptors. American Journal of Physiology $\mathbf{4 4}$ 1683-1689.

Thompson D, Pepys MB \& Wood SP 1999 The physiological structure of human C-reactive protein and its complex with phosphocholine. Structure 7 169-177. (https://doi.org/10.1016/S0969-2126(99)80023-9)

Vaiyapuri S, Kaiser W, Bicknell A, Gibbins J \& Lowry P 2017 Smokeinduced nausea; mediated by the release of the lung tachykinin, endokinin, into the circulation? Endocrine Abstracts 50 P270. (https:// doi.org/10.1530/endoabs.50.P270)

Vigushin DM, Pepys MB \& Hawkins PN 1993 Metabolic and scintigraphic studies of radioiodinated human C-reactive protein in health and disease. Journal of Clinical Investigation 91 1351-1357. (https://doi.org/10.1172/JCI116336)

Zulfikaroglu E, Ugur M, Taflan S, Ugurlu N, Atalay A \& Kalyoncu S 2007 Neurokinin B levels in maternal and umbilical cord blood in preeclamptic and normal pregnancies. Journal of Perinatal Medicine 35 200-202.

Received in final form 17 November 2017

Accepted 24 November 2017 http://jme.endocrinology-journals.org https://doi.org/10.1530/JME-17-0275
(C) 2018 Society for Endocrinology Published by Bioscientifica Ltd. Printed in Great Britain 